\title{
Studies on the influence of spent FCC catalyst on hydration of calcium aluminate cements at ambient temperature
}

\author{
B. Pacewska • M. Nowacka • I. Wilińska • \\ W. Kubissa • V. Antonovich
}

Received: 19 October 2010/Accepted: 4 January 2011/Published online: 3 March 2011

(c) The Author(s) 2011. This article is published with open access at Springerlink.com

\begin{abstract}
The influence of spent catalyst from catalytic cracking in fluidized bed (FCC) on the hydration of two kinds of calcium aluminate cements (of about 40 and $70 \%$ content of alumina) was studied. Cement pastes were prepared with constant ratio of water/binder $=0.5$ and with content of 0,5 and $25 \%$ mass of addition as replacement of cement. The samples were stored at room temperature. Thermal analysis (TG, DTG), infrared absorption (FTIR) and X-ray diffraction methods were applied to investigate changes in various periods of hydration (up to 150 days). The compressive strength of cement mortars was also examined. On the basis of presented results it was affirmed that in studied conditions spent FCC catalyst is a reactive addition in calcium aluminate cement (CAC) pastes, which probably can create a new phase type $\mathrm{C}-\mathrm{A}-\mathrm{S}-\mathrm{H}$. It may be an interesting alternative for limitation of the negative phenomenon of conversion of aluminate hydrates, although the degree of the influence of the mineral additive depends on the composition of CAC and of the quantity of the used waste.
\end{abstract}

Keywords Calcium aluminate cements - Spent FCC catalyst · Hydration · Conversion

B. Pacewska $(\bowtie) \cdot$ M. Nowacka $\cdot$ I. Wilińska $\cdot$ W. Kubissa Faculty of Civil Engineering, Mechanics and Petrochemistry, Warsaw University of Technology, Lukasiewicza $17 \mathrm{St}$, 09-400 Plock, Poland

e-mail: bpacewska@pw.plock.pl

V. Antonovich

Institute of Thermal Insulation, Vilnius Gediminas Technical University, Linkmenu 28, LT-08217 Vilnius, Lithuania

\section{Introduction}

Calcium aluminate cements (CACs) are quickly hardening hydraulic binders, which significantly differ in their chemical and phase compositions, properties and applications from often used Portland cements. They belong to special cements, recommended to be applied in situations, when the necessity of concreting in low temperatures or some properties of hardened cement materials such as: high early strength, resistance to chemical attack, fire resistance or resistance to abrasion are required. Because of their relatively high cost (CAC is more expensive than Portland cement) and possibility of deterioration of strength properties with time, even leading to building collapse (e.g., collapsing of the roofs in England in years 1973-1974) CACs are applied to structural concrete much less often than Portland cements [1-3]. The deterioration of strength is related with a process of conversion of aluminate hydrates. In case of CACs the nature of hydration products closely depends on time-temperature history of their formation. In the first order a hydration reactions of CACs at ambient temperature produce hexagonal hydrated calcium aluminates $\mathrm{CAH}_{10}$ and $\mathrm{C}_{2} \mathrm{AH}_{8}$ (abbreviations used in cement chemistry and thereby in this study: $C-\mathrm{CaO}$, $\left.A-\mathrm{Al}_{2} \mathrm{O}_{3}, S-\mathrm{SiO}_{2}, H-\mathrm{H}_{2} \mathrm{O}\right)$. However, the stable phases are $\mathrm{C}_{3} \mathrm{AH}_{6}$ (hydrogarnet) and $\mathrm{AH}_{3}$ (gibbsite), and other phases inevitably convert to these with time and/or at higher temperature as well as in favourable humidity. As a result, porosity of such cement material and its permeability increase with loss of strength of hardened concrete [1-6].

This problem has been investigated by many authors. They especially offered to use appropriate additions introduced into the cement system to avoid, or at least reduce, the hydrate conversion and its negative effect in CAC composites [2-17]. 
The most important applied additions contain silica. Silica component of the mineral addition introduced into hydrating CAC system gives possibility of alternative reaction way for the metastable hydrates by formation of new aluminate hydrate-containing silica-certain $\mathrm{C}-\mathrm{A}-\mathrm{S}-$ $\mathrm{H}$ phases-instead of conversion into the stable cubic hydrogarnet. Strätlingite, also called gehlenite hydrate$\mathrm{C}_{2} \mathrm{ASH}_{8}$ is most often proposed to be formed [2-13]. The strätlingite is a stable hydrate in the normal temperature and it improves strength properties after long time $[1,5]$. Ground granulated blast furnace slag [3, 5], fly ash $[4,6,7]$, silica fume $[4,6,8]$, microsilica [13] or natural pozzolans [9] introduced into CAC paste can react to produce this stable phase, although the amount of $\mathrm{C}_{2} \mathrm{ASH}_{8}$ in such complex system depends on the ability of the mineral admixtures to release silica. Chemical activity of silica can be increased in the presence of proper ions which act as a catalyst activating the surface of these extra grains. For example in case of natural zeolite better effect is obtained when sodium sulphate, sodium nitrate, sodium metaphosphate or sodium metasilicate are additionally used $[8,10$ 12].

The exact mechanism of chemical influence of silica and microstructure development in such cement system has not been univocally established yet. There are opinions that silica reacts in the hydrating CAC to produce various crystalline hydrates with changing proportions of $\mathrm{Ca}, \mathrm{Al}$ and $\mathrm{Si}$, such as: $\mathrm{C}_{3} \mathrm{AS}_{3-x} \mathrm{H}_{2 x},(0<x<3)$, and also different zeolite-type phases $[4,6,13,14]$.

Moreover, some authors [15] also used calcium carbonate as an additive counteracting the conversion process. In such cement matrix calcium carboaluminates were produced causing reduction of porosity and thus compensate the loss of strength during conversion.

Recently, satisfactory results of avoidance of the conversion were also obtained by use of supercritical carbon dioxide through the total carbonation of CAC hydrates [16].

Ettringite is another product arising instead of hydrogarnet. It can be formed in the $\mathrm{CaO}-\mathrm{Al}_{2} \mathrm{O}_{3}-\mathrm{CaSO}_{4}-\mathrm{H}_{2} \mathrm{O}$ system for example in the case when fly ash and calcium sulphate were added to CAC [17].

Spent catalyst from the fluidized catalytic cracking installation (named here as FBCC) is a fine-grained aluminosilicate material, porous and of well-developed specific surface. Its application in the cement matrix makes this material a sterling addition and it can be a profitable method of its utilization with economical and ecological benefits. It is especially important when we take into account the high price of CACs and possibility of limitation its quantity by partial replacement by cheaper material like spent catalyst. Profitable influence of this pozzolanic waste material on hydration of Portland cement was proved
$[18,19]$. However, in the literature no information about a role of spent catalyst as an agent limiting conversion of calcium aluminates in aluminate cement composites has been found.

The aim of this study was to investigate the effect of spent FCC catalyst on hydration of two types of CACs (of about 40 and $70 \%$ content of alumina) at ambient temperature. Thermal analysis (TG, DTG), infrared absorption (FTIR) and X-ray diffraction methods were used to identify changes in various periods of hydration (i.e., in the initial period and after long time) of cement pastes containing different amounts of this waste fine-grained aluminosilicate $(0,5$ and $25 \%$ mass in the substitution of cement). The compressive strength of cement mortars was also examined.

This article is a continuation of our previously published studies [20] on cement pastes with described waste catalyst.

\section{Experimental}

\section{Materials}

The studies were carried out with two types of CACs: Górkal 40 (called further as CAC 40) and Górkal 70 (CAC 70) produced by Górka Cement Sp. z o.o., Poland and waste petrochemical fluidal catalytic cracking catalyst (FBCC). The chemical and mineralogical composition of the raw materials is given in Table 1.

\section{Cement pastes preparation}

Cement pastes were produced using appropriate cement, spent FCC catalyst and distilled water. The amounts of the spent catalyst were: 0 (reference sample), 5 and $25 \%$ mass of the binder mass (binder $=$ cement + spent catalyst). The pastes were prepared with constant ratio of water/ binder equalling 0.5 . Cement and spent catalyst, both dry, were firstly mixed together, then water was added and then all components were mixed. Cement pastes were sealed in polyethylene bags and stored at temperature $23 \pm 2{ }^{\circ} \mathrm{C}$. After appointed time the hydration was stopped using acetone.

\section{Cement mortars preparation}

Cement mortars were prepared from grey CAC, CAC40 $(500 \mathrm{~g})$, standard quartz-sand CEN $(1350 \mathrm{~g})$ and tap water $(200 \mathrm{~g})$. In case of mortars with addition, part of the cement was replaced by 5 and $25 \%$ mass of spent FCC catalyst, respectively. The mortars were formed into triple moulds of dimensions $4 \times 4 \times 16 \mathrm{~cm}$ and the samples were stored according to PN-EN 14647 [24]. 
Table 1 The chemical and mineralogical composition of the raw materials [20-23]

\begin{tabular}{|c|c|c|c|c|c|}
\hline & $\mathrm{Al}_{2} \mathrm{O}_{3}(\%)$ & $\mathrm{CaO}(\%)$ & $\mathrm{SiO}_{2}(\%)$ & $\mathrm{Fe}_{2} \mathrm{O}_{3}(\%)$ & Minerals $^{\mathrm{a}}$ \\
\hline Grey CAC (CAC 40) & Min. 40 & Min. 36 & $2-4$ & Max. 14 & $\begin{array}{l}\text { Basic phase: CA Phase concurrent: } \\
\mathrm{C}_{4} \mathrm{AF}, \mathrm{C}_{12} \mathrm{~A}_{7} \text { and } \mathrm{C}_{2} \mathrm{AS}\end{array}$ \\
\hline White CAC (CAC 70) & $69-71$ & $28-30$ & Less than 0.5 & Less than 0.3 & $\begin{array}{l}\text { Basic phase: } \mathrm{CA}, \mathrm{CA}_{2} \text {, phase } \\
\text { concurrent: } \mathrm{C}_{12} \mathrm{~A}_{7} \text { and } \mathrm{Al}_{2} \mathrm{O}_{3}\end{array}$ \\
\hline Waste aluminosilicate catalyst FBCC & $38-41$ & $0.3-0.5$ & $50-54$ & $0.5-1.5$ & Zeolite \\
\hline
\end{tabular}

a Abbreviations according to symbols applied in the chemistry of cement: $C \mathrm{CaO}, \mathrm{A} \mathrm{Al}_{2} \mathrm{O}_{3}, S \mathrm{SiO}_{2}, \mathrm{~F} \mathrm{Fe}_{2} \mathrm{O}_{3}$

\section{Methods}

Cement pastes were investigated using:

- for thermal analysis (TG/DTG) TA Instruments SDT 2960 thermoanalyser, working in the temperature range up to $1000{ }^{\circ} \mathrm{C}$ in nitrogen atmosphere, at the heating rate of $10{ }^{\circ} \mathrm{C} \mathrm{min}^{-1}$, the sample mass was $9-13 \mathrm{mg}$, measurements were carried out after 3, 7, 14 and 150 days of cement hydration

- for IR studies Mattson FTIR Spectrometer Genesis II, IR spectra were recorded in the range of wave numbers $400-4000 \mathrm{~cm}^{-1}$, samples were prepared as $\mathrm{KBr}$ pellets, studies were carried out at the same time of cement hydration as in the case of TG and DTG measurements

- for X-ray diffraction Dron 7 diffractometer (anticathode-copper, anode voltage $30 \mathrm{kV}$, anode current $8 \mathrm{~mA}$ ), phase composition was identified using data from ICDD database, investigations were carried out after 150 days of hydration.

Cement mortars were tested for compressive strength according to EN 196-1 [25]:

- compressive strength after $6 h$ samples were kept in air at $20 \pm 2{ }^{\circ} \mathrm{C}$ and then they were removed from the moulds immediately before testing

- compressive strength after $24 \mathrm{~h}$ the remaining cubes were demoulded after $6 \mathrm{~h}$ and next they were kept under water at $20 \pm 1{ }^{\circ} \mathrm{C}$

- estimation of minimum long-term compressive strength the moulds were kept under water at $38 \pm 1{ }^{\circ} \mathrm{C}$, the samples were removed from the moulds after $24 \mathrm{~h}$ and then they were placed in water at $38 \pm 1{ }^{\circ} \mathrm{C}$ for 4 days.

\section{Results and discussion}

\section{Thermal analysis}

Thermal analysis allows to estimate composition of samples by measurements of loss of weight and thermal effects in definite temperature ranges. The complexity of cement pastes structure and the fact that registered effects depend on several variables including sample mass, heating rate, gas composition, flow rate and crucible geometry cause certain interpretative difficulties [26]. In literature the same products might have different temperature ranges of thermal decomposition, what was shown by Ukrainczyk [27].

In this study, peak temperature ranges for CAC hydrates were identified as follows [5, 6, 26-28]:

- in the range from 20 to $180{ }^{\circ} \mathrm{C}$ temperature peaks of dehydration of C-A-H gel and alumina gel can be observed at first and following peaks indicate a dehydration of $\mathrm{CAH}_{10}$ and $\mathrm{C}_{2} \mathrm{AH}_{8}$ hydrates. Temperature peaks of dehydration of phases type C-S-H or $\mathrm{C}-\mathrm{A}-\mathrm{S}-\mathrm{H}$ are also possible here, although these phases might occur only for samples with aluminosilicate additive

- in the range from 180 to $220^{\circ} \mathrm{C}$ a temperature peak can signify decomposition of strätlingite $\mathrm{C}_{2} \mathrm{ASH}_{8}$, a dehydration of possible carboaluminate phases (e.g., $\mathrm{C}_{4} \mathrm{AcH}_{11}$ ) and alternatively further dehydration of $\mathrm{C}_{2} \mathrm{AH}_{8}$

- in the range from 220 to $370{ }^{\circ} \mathrm{C}$ first temperature peak indicates dehydration of gibbsite $\mathrm{AH}_{3}$, and subsequent peak signifies dehydration of hydrogarnet $\mathrm{C}_{3} \mathrm{AH}_{6}$ and alternatively $\mathrm{C}_{3} \mathrm{AS}_{3-x} \mathrm{H}_{2 x}$ phase

- above $700{ }^{\circ} \mathrm{C}$ decomposition of carbonates occurs.

Thermal analysis of two types of CACs pastes (i.e., grey CAC40 and white CAC70 replaced by 0,5 and $25 \%$ masses with waste catalyst and hydrated at ambient temperature) was performed in initial periods of hydration (3rd, 7th and 14th day) and after long time-150 days. Obtained TG and DTG curves for studied mixtures are presented in Figs. 1, 2, 3 and 4, and characteristic of total mass loss in the range of $20-1000{ }^{\circ} \mathrm{C}$ for these samples is illustrated in Figs. 1 and 2. The results demonstrate (what was expected) the increase of concentration of hydrates as time progressed.

Influence of fine-grained spent FCC catalyst on hydration process is highly dependent on the type of aluminate cement as well as on the amount of introduced waste. In case of grey CAC40 cement the spent catalyst cause increase of the total mass loss in all studied periods for both 5 and $25 \%$ amount of addition in comparison with 
Fig. 1 The TG curves for CAC40 cement pastes containing $0 \%(1), 5 \%$ (2) and $25 \%$ (3) addition of spent FCC and the characteristic of total mass loss at different levels on hydration
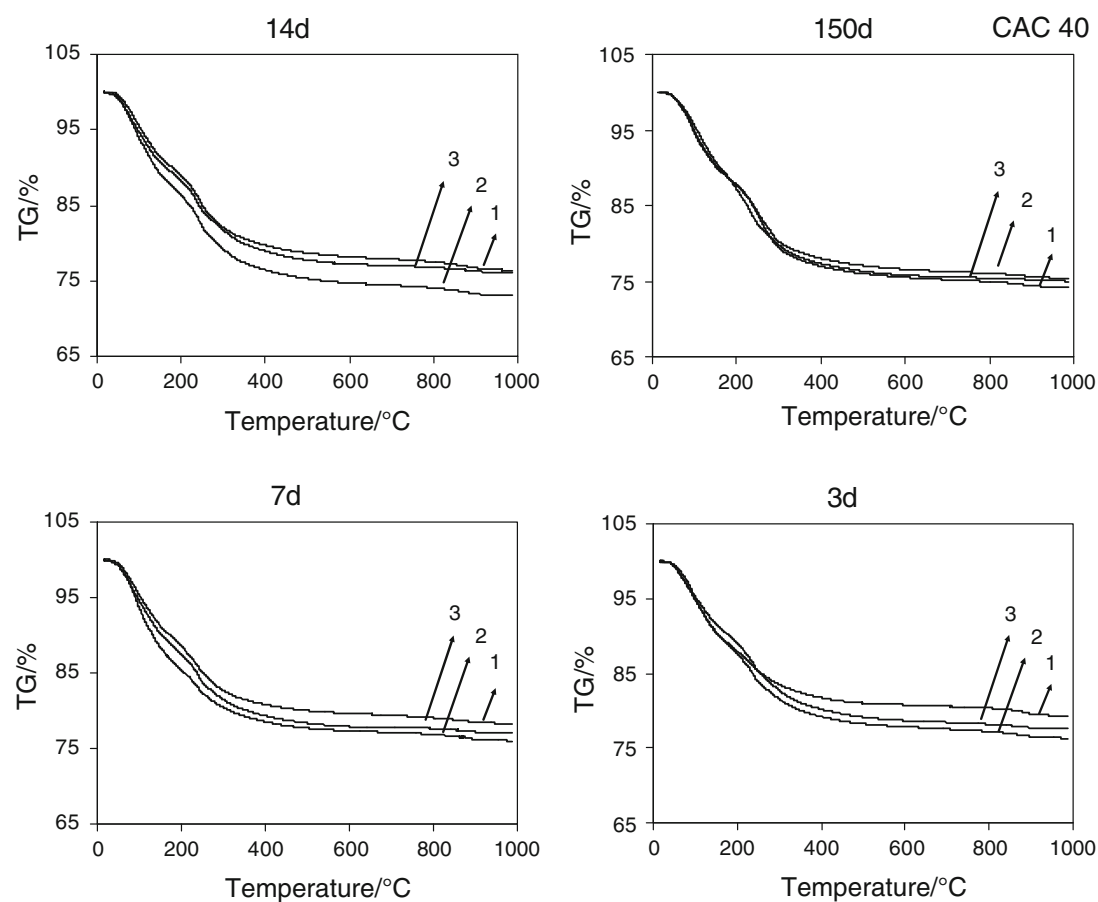

CAC 40

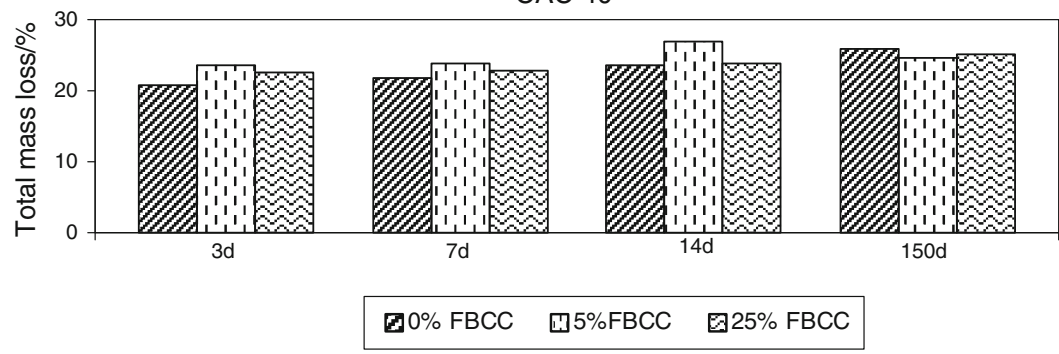

reference sample. The recorded total mass loss is largest in initial 3rd and 7th day of hydration for $5 \%$ content of aluminosilicate. After 150 days of hydration the differences are less visible. This fact is probably related to the acceleration of cement hydration (nucleative action) by this spent catalyst introduced into the grey CAC40 cement pastes which had been detected by calorimetric investigations in our earlier study [20]. A reduction of total mass loss was not detected even for samples containing $25 \%$ of spent catalyst, so it is possible to suppose that the waste is reactive in the cement matrix. Moreover, some ions can be released from the pores of the catalyst grains which can result in modification of hydration process.

In case of white CAC70 cement pastes the influence of $5 \%$ addition is favourable only on 3rd day of hydration. Such content of FBCC does not cause greater change at later ages of hydration in comparison with control sample. The increase of amount of waste to $25 \%$ causes considerable decrease of quantity of water bound in hydrates in initial periods. It might explain the fact that at first the waste catalyst introduced in such quantity into refractory cement matrix acts as microfiller similarly as amorphous silica [13], but with time the addition also undergoes chemical reactions and after 150 days of hydration the amounts of hydrates is comparable to the paste prepared without any FBCC content.

The acceleration effect of the addition in initial periods might result from zeolite structure of the waste aluminosilicate. Thanks to the structure this addition can adsorb water which causes better wettability of cement grains. The increase of total specific surface creates the nucleus of crystallization and greater development of hydrates.

In order to qualitatively identify the changes of hydration products, the detailed analysis of DTG curves in the range of temperature $20-500{ }^{\circ} \mathrm{C}$ was carried out. The majority of thermal decomposition of calcium aluminates and alternatively of calcium aluminosilicates occurs in this region (Figs. 3, 4).

Analysing DTG curves for both reference samples (made of CAC40 and CAC70 without the aluminosilicate addition) after 3 days of hydration at ambient temperature, the presence of alumina gel, $\mathrm{CAH}_{10}, \mathrm{C}_{2} \mathrm{AH}_{8}$ and $\mathrm{AH}_{3}$ 
Fig. 2 The TG curves for CAC70 cement pastes containing $0 \%(1), 5 \%$ (2) and $25 \%$ (3) addition of spent FCC and the characteristic of total mass loss at different levels on hydration
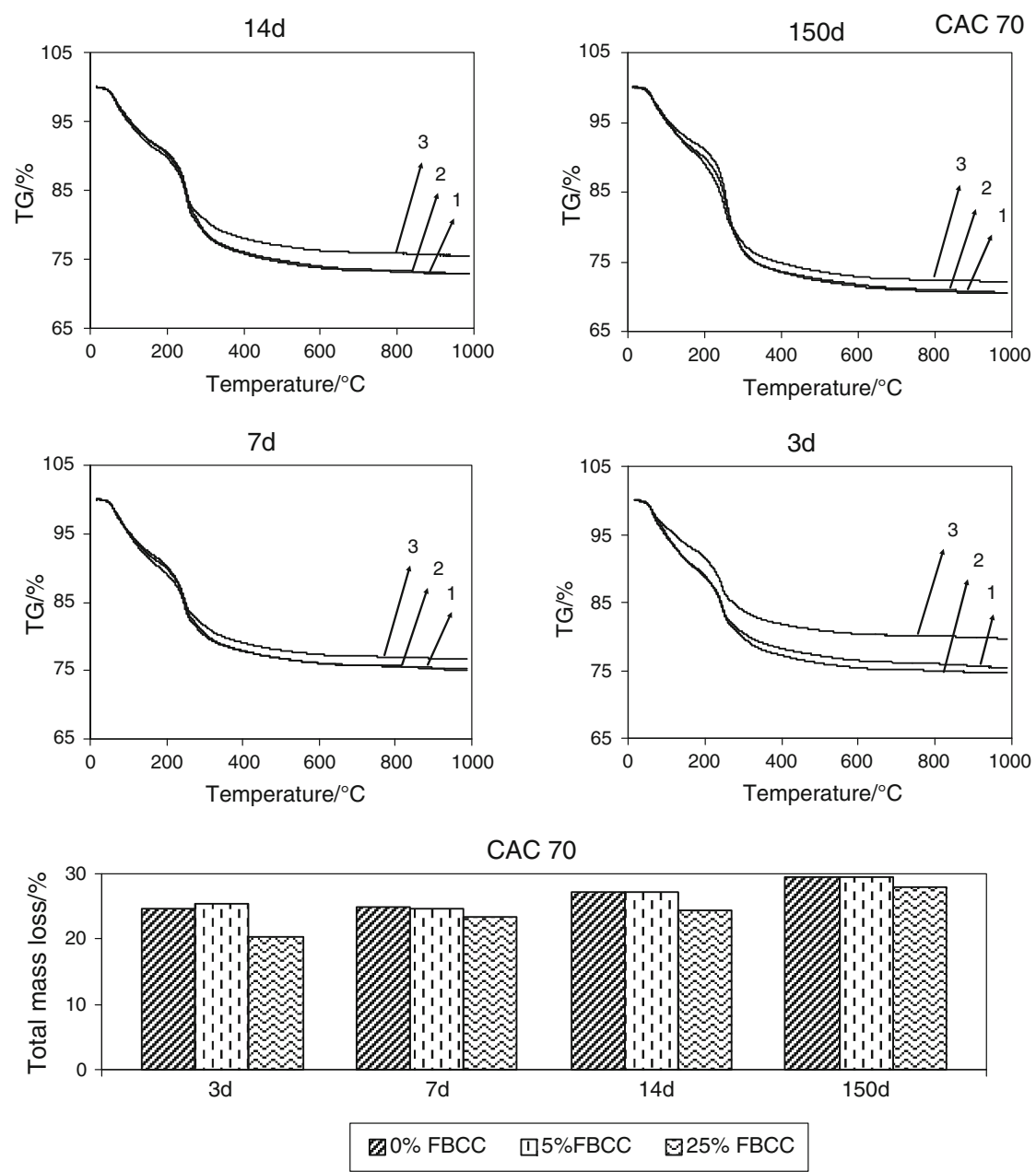

gibbsite corresponding to the temperature peaks at around $70,100,135$ and $250{ }^{\circ} \mathrm{C}$, respectively, is clearly visible. The peak of hydrogarnet at around $290{ }^{\circ} \mathrm{C}$ appears after 7 days of hydration.

The differences of intensity of respective temperature peaks depending on the kind of cement can confirm different proportions of hydration products in the studied systems. For grey CAC40 cement pastes the main products of hydration are hexagonal hydrates related to decomposition in temperature range $20-200{ }^{\circ} \mathrm{C}$, whilst in case of white CAC70 pastes the predominance of gibbsite presence is clearly marked (see curves 1 in Figs. 3, 4).

As time progresses the increase of intensity of gibbsite and hydrogarnet peaks with maxima at about 250 and $290{ }^{\circ} \mathrm{C}$, respectively, is observed - the largest after 150 days of hydration.

Comparing the changes of mass losses in individual temperature ranges for the control samples it should be noticed, that this increase of intensity in the range $220-370{ }^{\circ} \mathrm{C}$ is observed together with the decrease in the temperature range $20-180{ }^{\circ} \mathrm{C}$, what can prove conversion of hexagonal aluminates into thermodynamically stable phases occurring with time (Eqs. 1 and 2) [4]:

$3 \mathrm{CAH}_{10} \rightarrow \mathrm{C}_{3} \mathrm{AH}_{6}+2 \mathrm{AH}_{3}+18 \mathrm{H}$
$3 \mathrm{C}_{2} \mathrm{AH}_{8} \rightarrow 2 \mathrm{C}_{3} \mathrm{AH}_{6}+\mathrm{AH}_{3}+9 \mathrm{H}$.

Figures 3 and 4 present also DTG curves for CAC pastes with 5 and $25 \%$ mass of spent FCC catalyst, which show the influence of the addition on the type of forming products in comparison with reference paste.

For grey cement samples containing the mineral addition the intensity of gibbsite peak $\left(240{ }^{\circ} \mathrm{C}\right)$ on $3 \mathrm{rd}$ day of hydration is larger than in case of the paste without catalyst, which might confirm that addition of fine-grained waste aluminosilicate accelerates hydration of CAC40 [28].

In case of both CAC40 and CAC70 cement pastes containing waste catalyst, especially for $25 \%$ content, the delay of hydrogarnet forming, with maximum at $290{ }^{\circ} \mathrm{C}$, was observed. The hydrogarnet peak is present on 7 th day of hydration in samples without addition, whilst for pastes with $25 \%$ of waste it is not clearly visible even on 14th day 
Fig. 3 The DTG curves for CAC40 cement pastes containing $0 \%(1), 5 \%$ (2) and $25 \%$ (3) addition of spent FCC catalyst at different levels on hydration
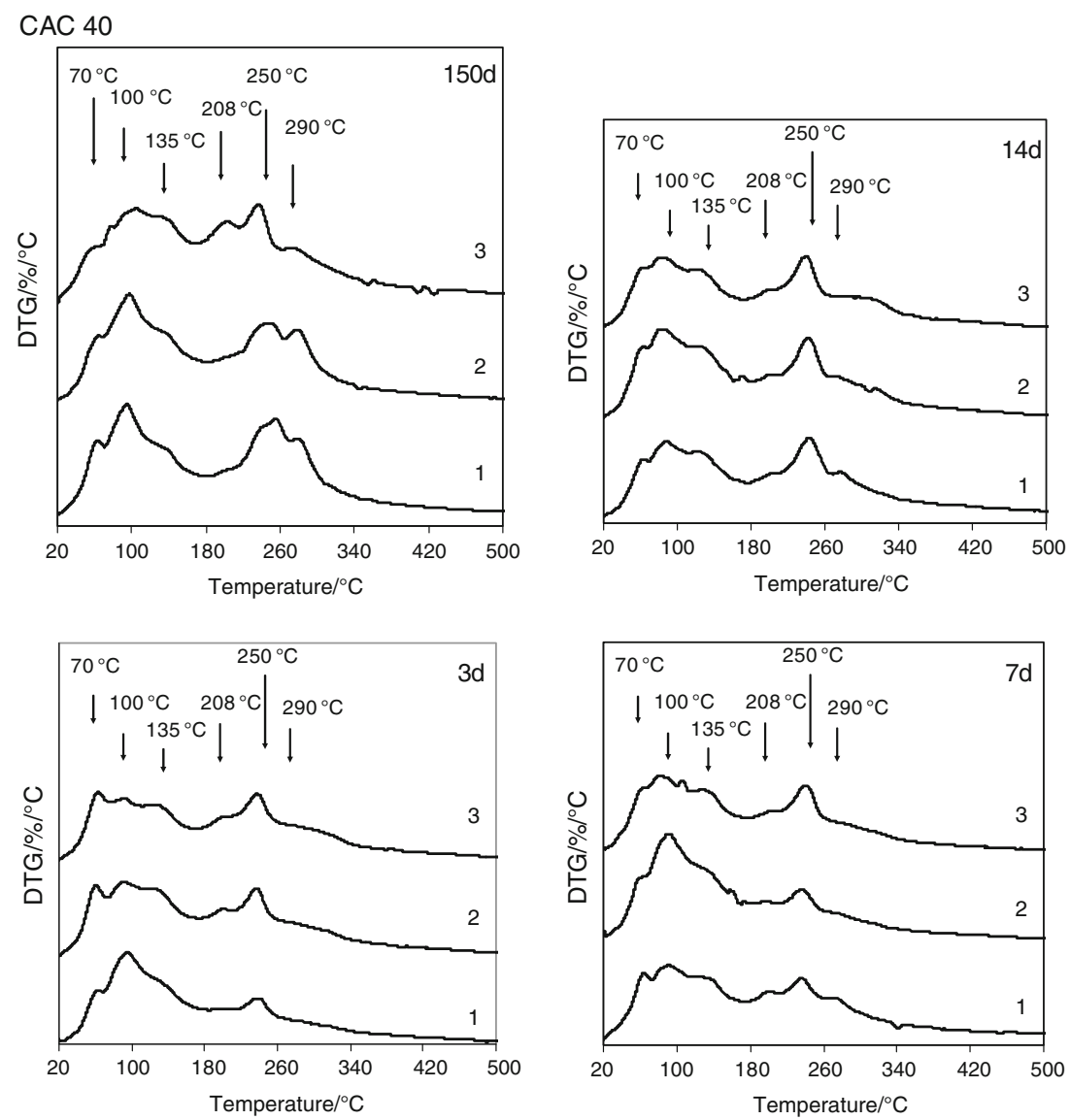

and after 150 days its intensity is distinctly lower than for the reference samples. Moreover, a limitation of gibbsite formation with time can be noticed; after 150 days of hydration the peak at $250{ }^{\circ} \mathrm{C}$ shows greater intensity in case of samples without addition than in case of mixture containing spent catalyst.

The influence of the waste aluminosilicate can be observed on DTG curves in temperature range $180-220^{\circ} \mathrm{C}$, with maximum at $208{ }^{\circ} \mathrm{C}$. In case of white cement CAC70 this peak of small intensity appears for the sample without waste catalyst only in initial periods and it is not present after 150 days, whilst in samples with addition of spent catalyst (particularly 25\%) it is clearly visible on 150th day of hydration. For the neat grey cement pastes very weak peak at $208{ }^{\circ} \mathrm{C}$ is visible on 7 th and 14 th day of hydration but it can not be distinguished neither on 3rd nor on 150th day. For CAC40 mixes with mineral addition this temperature peak is clearly visible already on 3rd day and it is more intensive after 150 days of hydration, especially for samples containing $25 \%$ of waste aluminosilicate. This temperature peak on DTG can indicate the presence of $\mathrm{C}_{2} \mathrm{AH}_{8}$ phase [27], so its disappearance with time, observed only for samples without the addition, proves the conversion process (Eq. 2). According to the Fig. 3, it can be seen that only for pastes containing the mineral addition the peak at about $208{ }^{\circ} \mathrm{C}$ increases with time of hydration. Spent FCC catalyst shows pozzolanic properties [18, 19], so its participation in the C-A-S-H type of hydrates formation is possible. On the basis of literature [26], the discussed peak can be identified as the one related to the presence of hydrated gehlenite $\mathrm{C}_{2} \mathrm{ASH}_{8}$ (known also as strätlingite) in aluminate cement paste containing aluminosilicate addition. It can confirm the previous assumption that waste catalyst is an active addition in CAC pastes which creates new phase competitive in the relation to cubic hydrogarnet.

Experimental study on effect of aluminosilicate addition on hydration of CAC indicates that mechanism of influence of this replacement material is different depending on the kind of CAC. It can be seen that in case of white cement CAC70 the primary function of spent FCC catalyst is acting as a microfiller and only at subsequent periods of hydration the silicate ions released from this waste aluminosilicate react with calcium aluminate hydrates such as $\mathrm{CAH}_{10}$ or $\mathrm{C}_{2} \mathrm{AH}_{8}$ to form strätlingite $\mathrm{C}_{2} \mathrm{ASH}_{8}$ (Eq. 3). Probably, C-S-H phase may first arise during reaction 
Fig. 4 The DTG curves for CAC70 cement pastes containing $0 \%(1), 5 \%(2)$ and $25 \%$ (3) addition of spent FCC catalyst at different levels on hydration
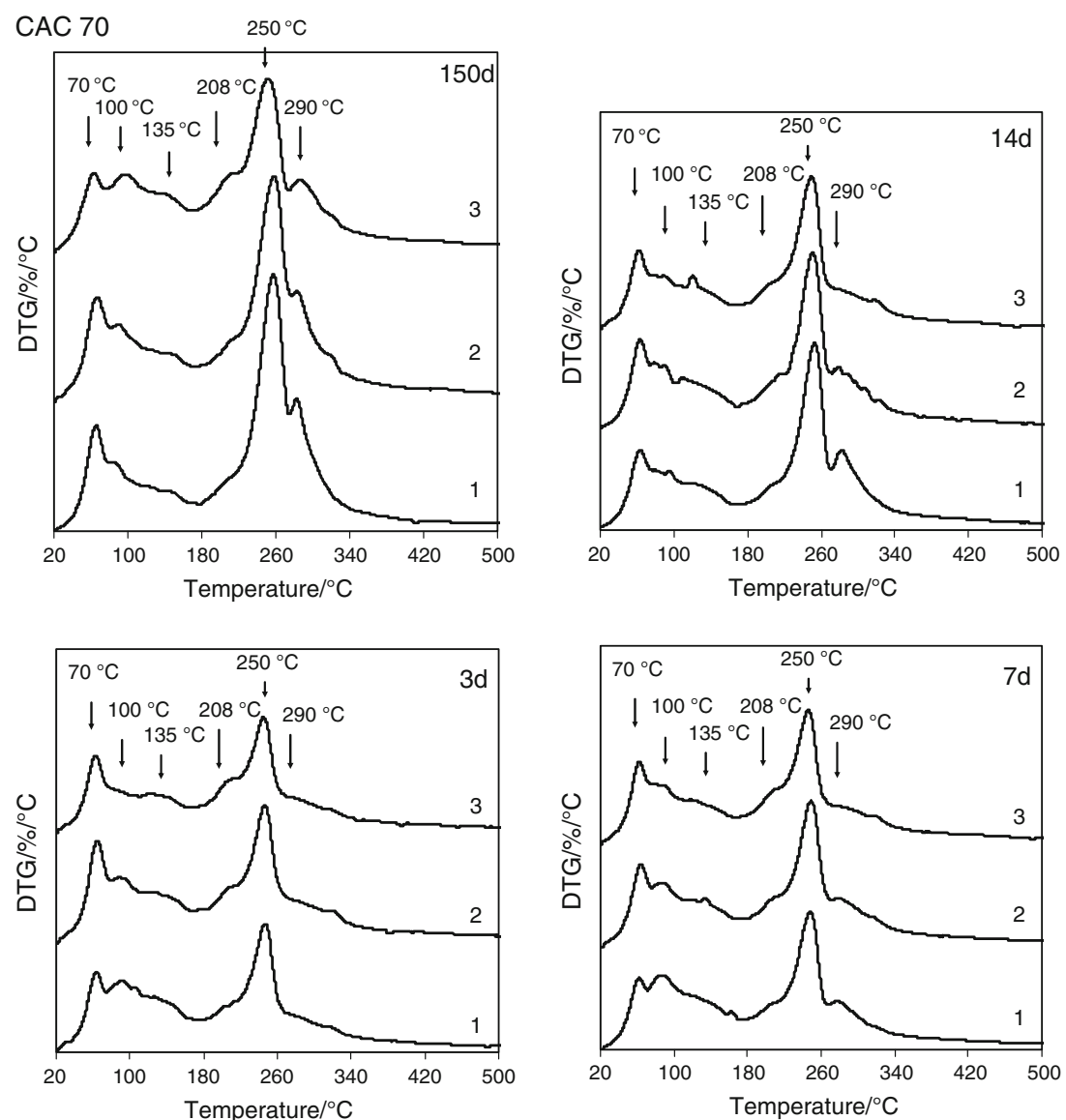

between silicate ions, originating from $\mathrm{FBCC}$, and $\mathrm{Ca}^{2+}$ from $\mathrm{CAC}$ hydration, and then it undergoes further reactions, for example according to this, given in [29]:

$\mathrm{C}_{2} \mathrm{AH}_{8}+2 \mathrm{CSH}+\mathrm{AH}_{3}+3 \mathrm{H} \rightarrow \mathrm{C}_{2} \mathrm{ASH}_{8}$.

However, in grey cement CAC40 pastes the studied addition seems to be chemically reactive already in initial periods and its action is more effective than in white cement matrix. The higher amount of hexagonal hydrates in CAC40 matrixes allows faster reaction of the FCC catalyst. It appears to be a way by which the conversion of hexagonal aluminate hydrates to $\mathrm{C}_{3} \mathrm{AH}_{6}$ may be limited.

\section{Infrared spectroscopy (FTIR)}

The analysis of IR spectra lets estimate the type of structures in studied systems. The complexity of compositions of cement pastes causes that the absorption bands overlap each other and it makes the identification difficult or even impossible.

The following regions of wave numbers may be distinguished for the CAC pastes: $3800-2500 \mathrm{~cm}^{-1}$-a broad, intensive bands related to stretching vibrations of $\mathrm{OH}$ groups in different hydrates, $1750-1310 \mathrm{~cm}^{-1}$-bands of bending vibrations of $\mathrm{H}-\mathrm{O}-\mathrm{H}$ molecules as well as bands connected with vibrations of $\mathrm{CO}_{3}{ }^{2-}$ groups; $1200-400$ $\mathrm{cm}^{-1}$-groups of absorption bands related to vibrations of $\mathrm{Al}-\mathrm{O}$ bonds in tetrahedra and octahedra as well as for $\mathrm{Si}-\mathrm{O}$ (in case of samples containing aluminosilicate additive). Recently, the detailed interpretation of IR spectra of CAC pastes has been described by Hidalgo et al. [4, 6].

Figures 5 and 6 present IR spectra for studied cement pastes (CAC40 and CAC70, respectively) with 5 and $25 \%$ content of spent catalyst (FBCC) in comparison with sample without addition at distant hydration levels (i.e., at 3rd and 150th day of hydration).

The shapes of IR spectra for CAC40 cement pastes (Fig. 5) on 3rd and 150th day of hydration are noticeably different. Broad band in the range of $3800-3200 \mathrm{~cm}^{-1}$ associated with alumina gel and $\mathrm{CAH}_{10}$ present on 3rd day clearly changes with time. The absorption peaks appearing at 3475,3530 and $3630 \mathrm{~cm}^{-1}$ due to $\mathrm{O}-\mathrm{H}$ stretch vibration in gibbsite prove the presence of this compound. The intensities of another gibbsite bands i.e., at 1027 and $979 \mathrm{~cm}^{-1}$ coming from $\mathrm{OH}$ bending vibration and at $534 \mathrm{~cm}^{-1}$ associated with $\mathrm{AlO}_{6}$ vibration also increase with time indicating the increase of gibbsite amount in all CAC40 cement pastes. Samples including spent catalyst in the mixture give lower gibbsite-resolved bands, especially 


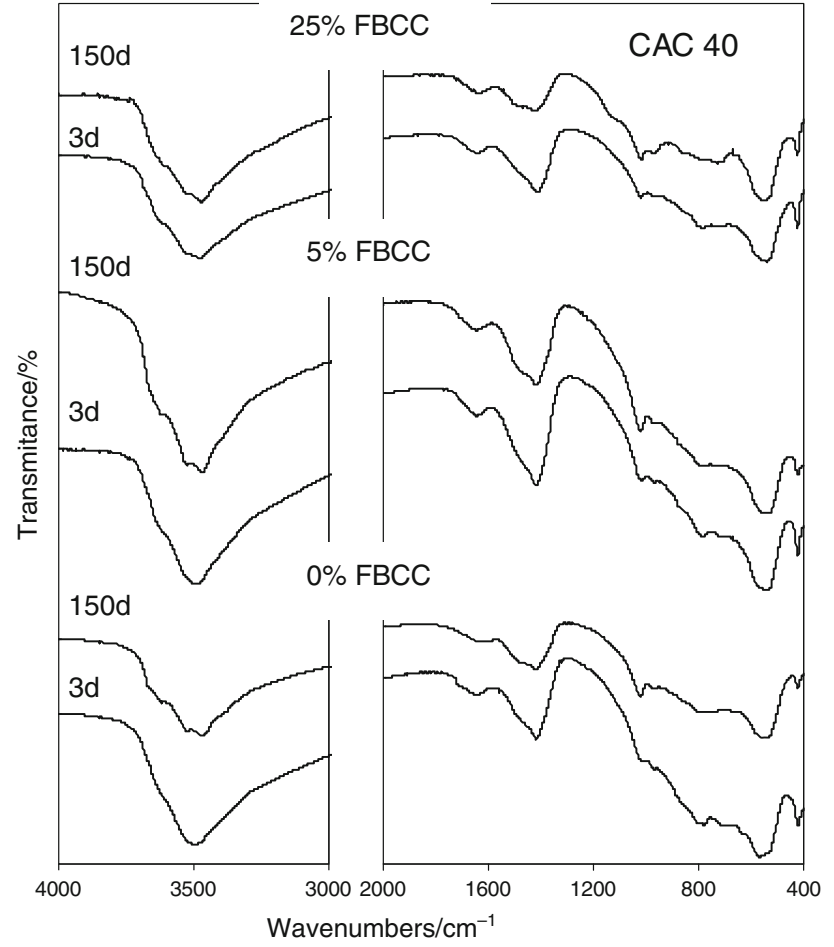

Fig. 5 IR spectra for grey CAC40 cement pastes with 0, 5 and $25 \%$ content of spent catalyst on 3rd and 150th day of hydration

for sample with $25 \%$ content of addition, indicating the presence of a less-crystalline aluminium hydroxide.

In case of CAC70 cement pastes the IR spectra (Fig. 6) show the bands at 3475,3530 and $3630 \mathrm{~cm}^{-1}$ and also at 1027 and $979 \mathrm{~cm}^{-1}$. These bands are diverse already on 7 th day of hydration. The increase in their intensity after 150 days is visible for both samples with the addition of the waste catalyst and also without the addition.

This observation confirms our previously discussed DTG/TG results indicating that quantity of gibbsite depends on the type of hydrating CAC and it's smaller for grey aluminate cement pastes containing $40 \%$ alumina (CAC40) than for samples on white aluminate cement pastes (CAC70).

The influence of FBCC on IR spectra of investigated pastes is observed as the differences at the region about $3666 \mathrm{~cm}^{-1}$, registered after 150 days. Small absorption band in this region is visible in pastes without addition and it is not separated when cement is substituted by $25 \%$ addition of spent catalyst. In CAC40 cement pastes the change is not as clearly visible as in CAC70 cases. According to literature $[4,6,17]$, the band can be assigned to hydrogarnet $\mathrm{C}_{3} \mathrm{AH}_{6}$. It should be noticed that the presence of hydrogarnet after long time of hydration can confirm the transformation of metastable hexagonal calcium aluminate hydrates to stable $\mathrm{C}_{3} \mathrm{AH}_{6}$ (Eqs. 1,2). On the other hand the waste catalyst limits formation of this

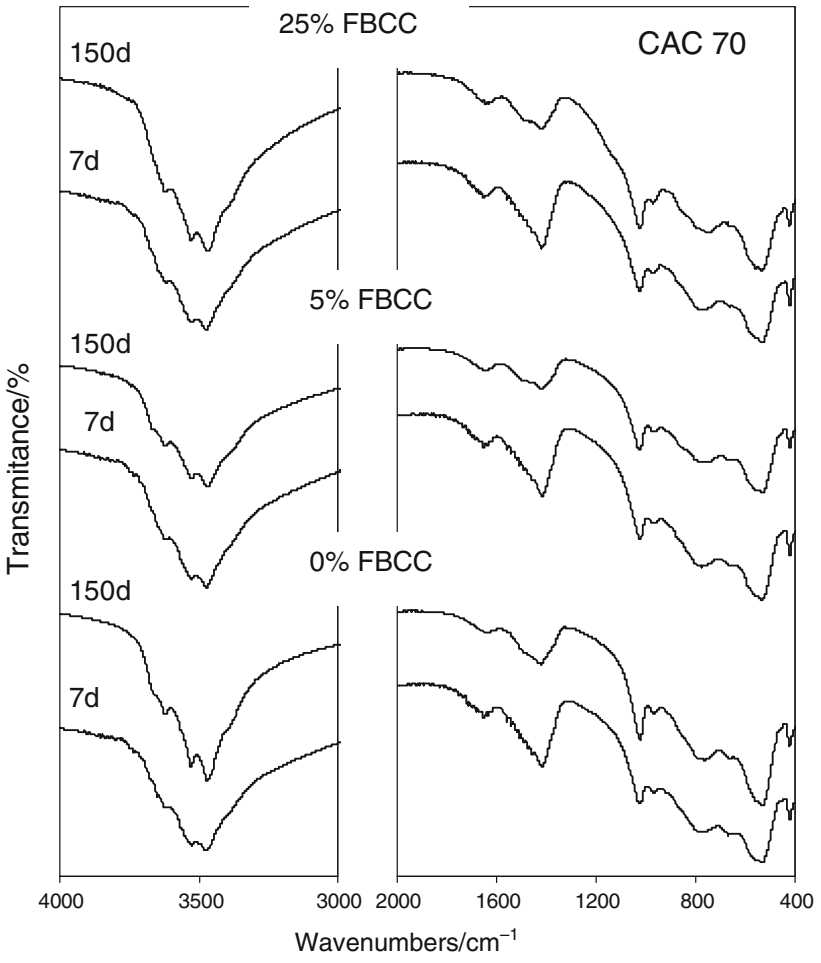

Fig. 6 IR spectra for white CAC70 cement pastes with 0,5 and $25 \%$ content of spent catalyst on 7th and 150th day of hydration

compound so it probably also prevents conversion process. However, absorption bands of members of the solid solution $\mathrm{C}_{3} \mathrm{AS}_{3-x} \mathrm{H}_{2 x}$ in the range $3660-3620 \mathrm{~cm}^{-1}$ have been also described [4].

In case of all samples bands at about $1639 \mathrm{~cm}^{-1}$ corresponding to the bending vibrations of $\mathrm{OH}$ in $\mathrm{HOH}$ and at about $1421 \mathrm{~cm}^{-1}$, the stretching vibrations of $\mathrm{CO}_{3}{ }^{2-}$ in carbonates are observed.

The area in the range of wave numbers $1200-400 \mathrm{~cm}^{-1}$ delivers the most interpretative difficulties. In this region many important bands are usually overlapped; for example the band occurring at about $970-968 \mathrm{~cm}^{-1}$ can be assigned to the bending vibrations of groups $\mathrm{O}-\mathrm{H}$ in gibbsite and alternatively to stretching vibrations of $\mathrm{Si}-\mathrm{O}$ in $\mathrm{C}-\mathrm{S}-\mathrm{H}$ type phase, similarly $664-662 \mathrm{~cm}^{-1}-\mathrm{Al}-\mathrm{O}$ in $\mathrm{AlO}_{6}$ in gibbsite or $\mathrm{Si}-\mathrm{O}-\mathrm{Si}, 457 \mathrm{~cm}^{-1}$ - bending vibrations of $\mathrm{O}-\mathrm{Si}-\mathrm{O}$ in $\mathrm{SiO}_{4}$, and at about $1122,800,553$ and $465 \mathrm{~cm}^{-1}$ stretching vibrations of $\mathrm{Si}-\mathrm{O}-\mathrm{Si}$ and $\mathrm{Al}-\mathrm{O}-\mathrm{Si}[4,6,17]$. However, it should be noticed that the presence of C-S-H can occur in the cement pastes with FBCC.

In case of CAC70 cement pastes it is not easy to demonstrate characteristic differences resulting from the presence of waste aluminosilicate in comparison with the reference sample in the considered ranges of wave numbers. Only very small bands at about $1145 \mathrm{~cm}^{-1}$ can be observed for the sample including $25 \%$ of FBCC after 150 days of hydration which might be interpreted as the 
$\mathrm{Si}-\mathrm{O}-\mathrm{Si}$ and $\mathrm{Al}-\mathrm{O}-\mathrm{Si}$ groups vibration resulting from addition of the replacement material [4]. Similar variation in the analogous sample of grey cement CAC40 is also apparent. The addition of FBCC causes larger differences for CAC40 cement pastes than for white CAC70 cement in this range of wave numbers.

However, absorption band with the maximum at $980 \mathrm{~cm}^{-1}$ occurs in all studied samples. Its highest intensity is registered when $25 \%$ content of waste is used. It might be explained by $\mathrm{Si}-\mathrm{O}$ stretching vibrations in C-S-H phase overlapping gibbsite peaks. Moreover, in samples with FBCC one can distinguish band at about $680 \mathrm{~cm}^{-1}$ possible relating to $\mathrm{Si}-\mathrm{O}-\mathrm{Si}$ groups vibrations.

Although the unambiguous identification of individual hydrates through the IR spectra analysis is not possible, it can conclude that the influence of addition on hydration of cement is larger in case of grey CAC40 cement pastes than for the CAC70 samples.

\section{$X$-ray diffraction}

The X-ray diffraction method allows to recognize the crystalline structure of cement pastes [3,6,11]. Figures 7 and 8 present diffraction patterns at 150 days of hydration for studied pastes. Comparing the results obtained for reference samples made of CAC40 and CAC70 (Figs. 7, 8, respectively) one may notice considerable differences of hydration products that are found in these various kinds of aluminate cement pastes. After 150 days of hydration the stable $\mathrm{C}_{3} \mathrm{AH}_{6}$ and crystalline gibbsite as well as hexagonal hydrates $\mathrm{CAH}_{10}$ and $\mathrm{C}_{2} \mathrm{AH}_{8}$ are identified. Anhydrous phases such as non-reacted monoaluminates $\mathrm{CA}$ and, in case of grey $\mathrm{CAC} 40$ also non-reacted ferrite $-\mathrm{C}_{4} \mathrm{AF}$ and gehlenite phases $-\mathrm{C}_{2} \mathrm{AS}$ are still present at these advanced stages.
For mixes with spent FCC catalyst the insignificant effect of 5\% amount of FBCC on studied cementitious matrix is noticed. Only in case of CAC70 pastes the intensity of $\mathrm{C}_{2} \mathrm{AH}_{8}$ diffraction peaks increases when $5 \%$ of this waste aluminosilicate is used. The crystalline structure of hydrating aluminate cement system is considerably different when $25 \%$ of FBCC is added. Both in the case of grey and white aluminate cement it is quite clear that the presence of such quantity of this mineral addition causes decrease of the intensity of $\mathrm{CAH}_{10}$ and $\mathrm{C}_{2} \mathrm{AH}_{8}$, and also $\mathrm{C}_{3} \mathrm{AH}_{6}$ peaks in comparison with samples without the waste. Moreover, the new crystalline hydrates type of C-A$\mathrm{S}-\mathrm{H}$ are described, e.g., strätlingite $\mathrm{C}_{2} \mathrm{ASH}_{8}$ is detected. It is visible especially clear for grey CAC 40 cement pastes.

The presence of this type of hydrate in binary CAC70-25\% FBCC system can confirm the fact that the spent catalyst leads to formation of new products, so it is chemically reactive addition (Eq. 3).

In case of grey CAC40 cement the gehlenite phase $\mathrm{C}_{2} \mathrm{AS}$ naturally occurs in this binder and theoretically it might react with water to produce strätlingite $\mathrm{C}_{2} \mathrm{ASH}_{8}$ (Eq. 4) [30]:

$$
\mathrm{C}_{2} \mathrm{AS}+8 \mathrm{H} \rightarrow \mathrm{C}_{2} \mathrm{ASH}_{8} .
$$

However, $\mathrm{C}_{2} \mathrm{AS}$ is cement phase of low hydraulic activity and this non-reacted form is still found after 150 days of hydration. The appearance of $\mathrm{C}_{2} \mathrm{ASH}_{8}$ in CAC40-25\% FBCC matrix might prove the reactivity of the waste aluminosilicate.

Arising of the new type of hydrate formed with simultaneous reduction of the content of cubic $\mathrm{C}_{3} \mathrm{AH}_{6}$ in the samples in which the waste catalyst was applied can also prove that the spent FCC catalyst limits transformation of hexagonal hydrate into $\mathrm{C}_{3} \mathrm{AH}_{6}$.
Fig. 7 X-ray diffraction patterns for CAC40 cement pastes containing different amounts of spent catalyst after 150 days of hydration at ambient temperature

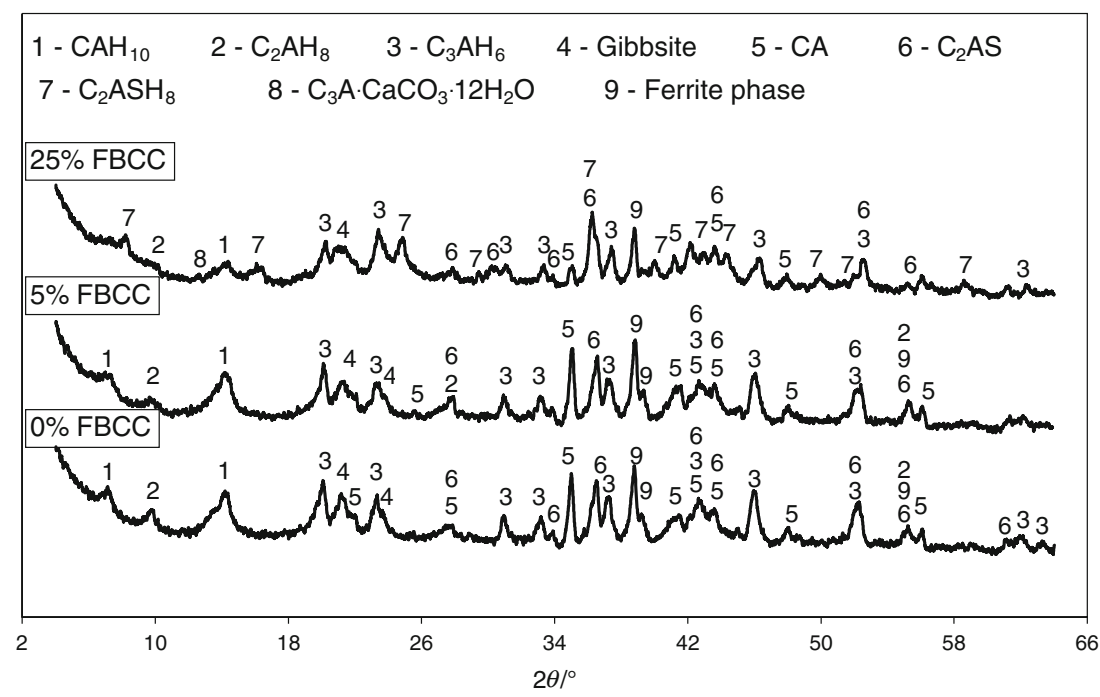


Fig. 8 X-ray diffraction patterns for CAC70 cement pastes containing different amounts of spent catalyst after 150 days of hydration at ambient temperature

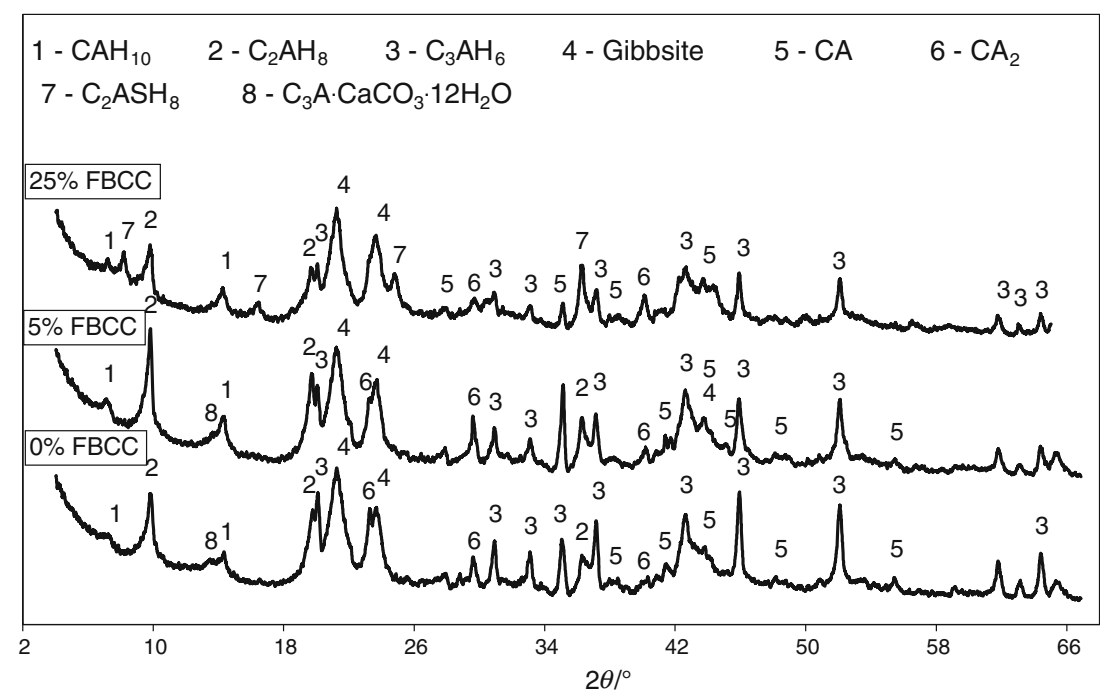

\section{Compressive strength}

The fast hydration of CACs causes characteristic rapid strength development. The value of initial strength (up to $60 \mathrm{MPa}$ after $24 \mathrm{~h}$ ) is part of $\sim 85 \%$ of the final strength, which reaches to $80 \mathrm{MPa}$ even after 14 days. The hardened material gains strength rapidly, so much so that its compressive strength after $24 \mathrm{~h}$ of curing is comparable with the strength of Portland cement after about 28 days. Therefore, the PN-EN 14647 standard [24] concerning the study of CAC recommends to investigate the compressive strength after 6 and after $24 \mathrm{~h}$.

However, one can not apply these values of strength for projecting the concrete, because of decrease in compressive strength with time, associated with conversion. That is why the standard also gives the method of assessment of minimum long-term compressive strength (estimated value of compressive strength 'after conversion').

The compressive strength of CAC 40 mortars with 5 and $25 \%$ mass of spent catalyst in comparison with the reference samples made without any FBCC content was studied.

Rapid development of early compressive strength for studied mortars is shown (Fig. 9): for the reference sample the value after $6 \mathrm{~h}$ amounts to $26 \mathrm{MPa}$ and reaches above $47 \mathrm{MPa}$ after $24 \mathrm{~h}$. Investigation of estimation of minimum long-term strength by fabricating analogous mortars showed the expected decrease of compressive strength to almost $38 \mathrm{MPa}$, so it is about $19 \%$ less in relation to the level after $24 \mathrm{~h}$.

First, on the stage of preparing of mortars the physical influence of the fine-grained zeolite-type aluminosilicate addition is evident. 5\% content of spent catalyst improves workability of mortars whilst $25 \%$ mass of this waste causes consolidation of mortars with difficulty (superplasticizer should be used here in the future).

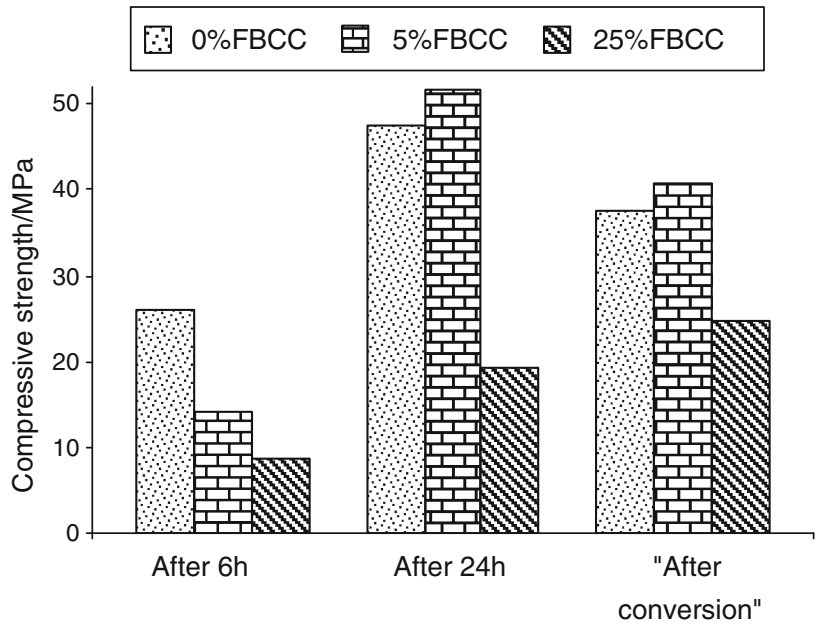

Fig. 9 The change of compressive strength after $6 \mathrm{~h}$, after $24 \mathrm{~h}$ and the so-called minimum value of long-term strength ('after conversion') of the CAC40 mortars with the various content of spent catalyst as substitution of part of cement

Consistently, the amount of introduced waste shows the principal influence on the value of compressive strength (Fig. 9). Addition of $25 \%$ of spent catalyst, in such composition of mortars, causes reduction of strength unacceptable in practical application. However, analyzing the change of compressive strength after $6,24 \mathrm{~h}$ and 'after conversion', only for samples containing $25 \%$ additive the increase of strength (not fall 'after conversion') is observed. This fact is related with progressive reaction of waste aluminosilicate in studied mixes and at conditions of investigations (storage in water) to form strätlingite $\mathrm{C}_{2} \mathrm{ASH}_{8}$ instead of $\mathrm{C}_{3} \mathrm{AH}_{6}$ (which was detected by XRD).

Content of $5 \%$ of spent FCC catalyst reduces compressive strength after $6 \mathrm{~h}$ (about 45\%), improves compressive strength after $24 \mathrm{~h}$ (about 9.3\%), and also improves 
minimum long-term strength of mortars (about $8.5 \%$ ) in the comparison with the mortars without the addition. Although such quantity of waste catalyst does not prevent the drop of strength being the result of conversion, the value of minimum long-term strength ('after conversion') based on mortars is higher than for sample without the addition.

\section{Conclusions}

On the basis of obtained results one can conclude that:

- hydration of aluminate cement is closely dependent on the type of aluminate cement (what was expected) and leads to produce the structure of different proportions of hydrates (comparison of results for grey and white cement); in case of cement with higher amount of alumina the gibbsite present is favoured, whilst for cement with less alumina content the hexagonal hydrates are more visible

- the structure of the hardened material cured at ambient temperature is time dependent (what was expected too); as time progressed to 150 days the conversion of metastable hexagonal hydrates into stable products was observed

- fine-grained spent catalyst from FCC installation used as cement substitution additive influences the hydration of aluminate cement in the studied stages depending on kind of cement as well as on quantity of introduced waste; the influence is more effective in case of grey CAC (CAC40) than for white CAC70 cement pastes

- the content of $5 \%$ of studied waste material, in both grey and white aluminate cement cases accelerates creating of hydrates (also stable forms) at initial hydration periods, thus it is possible to confirm that catalyst grains act as nucleation centres. Also liberated ions can result in an acceleration of hydration processes. Influence of such quantity of addition in relation to both cements after the long time of hydration is rather insignificant

- the influence of $25 \%$ content of waste aluminosilicate in initial periods of hydration is related to type of cement; the primary function of spent FCC catalyst in white (CAC 70) aluminate cement matrix is to act as a filler, whilst in grey CAC40 cement pastes this mineral additive reacts to produce more amounts of hydrates than for reference sample; in later stages the chemical activity of discussed waste material in CAC70 cement pastes was also observed

- XRD results confirm the reactivity of the additive; the new alumino-silicate hydrate $\mathrm{C}-\mathrm{A}-\mathrm{S}-\mathrm{H}$ types, described as strätlingite $\mathrm{C}_{2} \mathrm{ASH}_{8}$ was identified in the presence of FBCC; its appearance limits the formation of cubic hydrogarnet as a product of conversion process; the kinetics of strätlingite formation depends on the composition of aluminate cement

- study on the compressive strength of CAC40 cement mortars containing discussed addition indicates that the value of long-term strength for studied mortars is profitably modified by the presence of waste aluminosilicate; it is possible to suppose that the increase of the compressive strength is due to the formation of strätlingite instead of hydrogarnet; however, considering the application of this spent FCC catalyst the optimum amount of the waste should be qualified as well as the introduction of additional substances, e.g., superplasticizer.

Summing up, we should notice that spent FCC catalyst reacts in $\mathrm{CAC}$ pastes hydrated at ambient temperature with formation of the new hydrate of the type of C-A-S-H competitive in the relation to cubic $\mathrm{C}_{3} \mathrm{AH}_{6}$ which limits the disadvantageously conversion process. Thus, this waste material, for which the profitable influence on Portland cement composites was confirmed earlier, probably can also replace a part of aluminate cement leading to obtain binder with modified properties.

This study is an introduction to more extensive investigation of the CAC-FBCC mixtures, which allow to define the degree of the reactivity of the addition and the forming structure more exactly.

Open Access This article is distributed under the terms of the Creative Commons Attribution Noncommercial License which permits any noncommercial use, distribution, and reproduction in any medium, provided the original author(s) and source are credited.

\section{References}

1. Bensted J. Scientific aspects of high alumina cement. Cem Lime Concr. 2004;3:109-33.

2. Hewlett PC. Lea's chemistry of cement and concrete. 4th ed. New York: Arnold: Chemical Publishing Co; 2004.

3. Quilllin K, Osborne G, Majumdar A, Singh B. Effect of w/c ratio and curing conditions on strength development in BRECEM concretes. Cem Concr Res. 2001;31:627-32.

4. Hidalgo Lopez Ana, Garcia Calvo JL, Garcia Olmo J, Petit S, Cruz Alonso M. Microstructural evolution of calcium aluminate cements hydration with silica fume and fly ash additions by scanning electron microscopy, and mid and near-infrared spectroscopy. J Am Ceram Soc. 2008;91(4):1258-65.

5. Heikal M, Morsy MS, Radwan MM. Electrical conductivity and phase composition of calcium aluminate cement containing aircooled and water-cooled slag at 20,40 and $60{ }^{\circ} \mathrm{C}$. Cem Concr Res. 2005;35:1438-46.

6. Hidalgo A, Garcia JL, Alonso MC, Fernandez L, Andrade C. Microstructure development in mixes of calcium aluminate cement with silica fume or fly ash. J Therm Anal Calorim. 2009; 96(2):335-45.

7. Collepardi M, Monosi S, Piccioli P. The influence of pozzolanic materials on the mechanical stability of aluminous cement. Cem Concr Res. 1995;25(5):961-8. 
8. Ding J, Fu Y, Beaudoin JJ. Stratlingite formation in high alumina cement-silica fume system: significance of sodium ions. Cem Concr Res. 1995;25(6):1311-9.

9. Fu Y, Ding J, Beaudoin JJ. Zeolite-based additives for high alumina cement products. Advn Cem Bas Mat. 1996;3:37-42.

10. Ding J, Fu Y, Beaudoin JJ. Effect of different inorganic salts/ alkali on conversion-prevention in high alumina cement products. Advn Cem Bas Mat. 1996;4:43-7.

11. Ding J, Fu Y, Beaudoin JJ. Study of hydration mechanisms in the high alumina cement-sodium silicate system. Cem Concr Res. 1996;26(5):799-804.

12. Fu Y, Ding J, Beaudoin JJ. US Patent 5,624,489. 1997.

13. Rivas Mercury JM, Turrilas X, Aza AH, Pena P. Calcium aluminates hydration in presence of amorphous $\mathrm{SiO} 2$ at temperatures below 90 C. J Solid State Chem. 2006;179:2988-97.

14. Pena P, Rivas Mercury JM, de Aza AH, Turrillas X, Sobrados I, Sanz J. Solid-state 27Al and 29Si NMR characterization of hydrates formed in calcium aluminate-silica fume mixtures. J Solid State Chem. 2008;181:1744-52.

15. Darweesh HHM. Limestone as an accelerator and filler in limestone-substituted alumina cement. Ceram Int. 2004;30:145-50.

16. Fernández-Carrasco L, Rius J, Miravitlles C. Supercritical carbonation of calcium aluminate cement. Cem Concr Res. 2008;38: 1033-7.

17. Fernández-Carrasco L, Vázquezi E. Reactions of fly ash with calcium aluminate cement and calcium sulphate. Fuel. 2009;88: 1533-8.

18. Garcia de Lomas M, Sanchez de Rojas MI, Frias M. Pozzolanic reaction of a spent fluid catalytic cracking catalyst in FCCcement mortars. J Therm Anal Calorim. 2007;90(2):443-7.

19. Payá J, Monzó J, Borrachero MV, Garcés P, Mellado A, Velázquez S, Soriano L, Zornoza E. Outstanding aspects on the use of spent FCC catalyst in binders. In: 1st Spanish National Conference on Advances in Materials Recycling and Eco-Energy, Madrid, p. 12-13, November 2009.
20. Pacewska B, Wilińska I, Bukowska M. Calorimetric investigations of the influence of waste aluminosilicate on the hydration of different cements. J Therm Anal Calorim. 2009;97(1):61-6.

21. Information of Górkal cement producer, published on a webpage: www.gorka.com.pl.

22. Pacewska B, Wilińska I, Nowacka M, Pundiene I, Aleknevicius M. Studies on the influence of aluminosilicate additive on initiation steps of high calcium aluminate cement hydration. In: 10th International Conference "Modern Building Materials, Structures and Techniques", Wilno, Litwa, 2010.

23. Antonovic V, Baltrenas P, Aleknevicius M, Pundiene I, Stonys R. Modification of petrochemical fluid catalytic cracking catalyst waste properties by treatment in high temperature. In: 10th International Conference "Modern Building Materials, Structures and Techniques", Wilno, Litwa, 2010.

24. Standard PN-EN 14647. Calcium aluminate cement-Composition, specifications and conformity criteria.

25. Standard EN 196-1. Methods of testing cement Part 1: determination of strength.

26. Ramachandran VS, Paroli RM, Beaudoin JJ, Delgado AH. Handbook of thermal analysis of construction materials. New York: Noyes Publications, William Andrew Publishing; 2002.

27. Ukrainczyk N, Matusinovic T, Kurajica S, Zimmermannb B, Sipusic J. Dehydration of a layered double hydroxide-C2AH8. Thermochim Acta. 2007;464:7-15.

28. Nilforoushan MR, Talebian N. The hydration products of a refractory calcium aluminate cement at low temperatures. Iran $\mathrm{J}$ Chem Chem Eng. 2007;26(2):71-6.

29. Nithya R, Barathan S, Govindarajan D, Raghu K, Anandhan N. A thermal study on blended ternary cement paste. Int J Chem. 2010;2(1):121-7.

30. Lou W, Guan B, Wu Z. Calorimetric study of ternary binder of calcium aluminate cement, Portland-limestone cement and FGD gypsum. J Therm Anal Calorim. 2010;101(1):119-27. 